\title{
First Report of SARS-CoV-2 Gamma Variant in Turkey
}

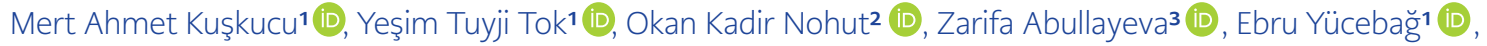

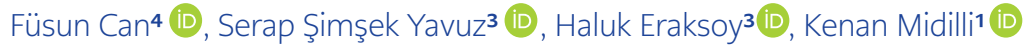 \\ 1 Department of Medical Microbiology, İstanbul University Cerrahpaşa School of Medicine, İstanbul, Turkey \\ 2 Department of Medical Biochemistry, İstanbul University Cerrahpaşa School of Medicine, İstanbul, Turkey \\ 3 Department of Infectious Diseases and Clinical Microbiology, İstanbul University Çapa School of Medicine, İstanbul, Turkey \\ 4 Department of Medical Microbiology, Koç University School of Medicine, İstanbul, Turkey
}

\begin{abstract}
Keeping track of SARS-CoV-2 variants of concern (VOC) is crucial to inform public health efforts and limiting the ongoing pandemic. Here, we describe the first detection of SARSCoV-2 P.1 lineage in Turkey. The fact that new variants can be detected in every geography of the world indicates the need for more whole genome sequencing in order to better understand virus dynamics and take earlier action.
\end{abstract}

Keywords: SARS-CoV-2, P.1 lineage, Variant of Concern (VOC), mutations

\section{INTRODUCTION}

A $s$ viruses spread through a population, they mutate and change, leading to the evolution of slightly different forms or variants. SARS-CoV-2 has been mutating ever since it was first detected in Wuhan, China, in December 2019. While most of the mutations will not have a significant effect on the spread of the virus, some mutations or combinations of mutations may provide virus advantages such as increased transmissibility or the ability to evade the host immune response. In such cases, these variants are more risky for human health and are considered to be variants of concern (VOCs) (1). Currently, the detectable virus mutation rate is once or twice a month. The speed of virus mutation is related to the number of cases in the World; the more we bring down the case numbers, the slower the virus will mutate (2). As of March 2021, there are three variants accepted as VOC; the Alpha SARS-CoV-2 variant (B.1.1.7GR/501Y.V1), the Beta SARS-CoV-2 variant (B.1.351-GH/501Y.V2), the Gamma SARSCoV-2 variant (P.1-GR/501Y.V3) (3). Although the Alpha SARS-CoV-2 variant (B.1.1.7) has increased transmissibility compared to previously circulating variants, no increase in infection severity has so far been identified. While the Alpha SARS-CoV-2 variant (B.1.1.7) continues to cause more than a half of new COVID-19 cases in Turkey, the focus has currently shifted to the potential for import of other new variants that also be

\section{Corresponding Author: Yeşim Tuyji Tok \\ E-mail: \\ dr.yesimtok@gmail.com}

Received: May 3, 2021

Accepted: July 5, 2021

Published: August 31, 2021

Suggested citation: Kuşkusu MA, Tuyji-Tok Y, Nohut OK, Abullayeva Z, Yücebağ E, Can F, et al. First report of SARSCoV-2 gamma variant in Turkey. Infect Dis Clin Microbiol 2021; 2: 97-99.

DOI: $10.36519 / \mathrm{idcm} .2021 .43$ 
more infectious, mortal and demonstrate immune or vaccine escape based on mutations in the S protein (4). Cases of the Beta variant (B.1.351/ 501Y. V2) have already been reported in Turkey, but the Gamma variant is not detected before this case (3).

\section{CASE PRESENTATION}

We report a case announced as the first SARSCoV-2 infection with the Gamma SARS-CoV-2 variant P.1-GR/501Y.V3 by the government on 2 March 2021. A 48-year-old male patient, from whom the virus was isolated, was a businessman with a history of hypertension who returned to Turkey from Brazil. The possible source of infection was Brasilia airport, where he had to wait for a long time. He had no contact from his arrival in Turkey until his hospitalization, and his 14-day treatment, including oxygen support, was done in the isolated room in the COVID-19 department. Viral nucleic acid isolation from the oropharyngeal/nasal swab sample was performed by the RTP $®$ Pathogen commercial kit (Stratec Molecular, Germany) and tested for SARS-CoV-2 by multiplex real-time PCR using SARS-CoV-2 assay GeneMAPTM 2019-nCoV (SARSCoV-2) Detection Kit (nCoV-RT100) (GeneMARK) in accordance with manufacturer's instructions. Cycle threshold values (Cts) for targeting the RNA-dependent RNA polymerase (RdRp) and the $\mathrm{N}$ genes were 23 and 25. In preparing libraries for next-generation sequencing; Following the preparation of cDNA by reverse transcription from RNA samples, the COVID-19 genome was replicated using the CleanPlex® Research NGS Panel (Paragon Genomics, Inc., USA) kit using the multiple PCR method containing 343 overlapping amplicons with amplicon sizes an average of 149 bp. Later, fragmentation and tagmentation processes of PCR samples were performed with Nextera TM DNA Flex Library Prep (Illumina, USA) kit. Next-generation sequencing was performed using Illumina MiniSeq device "high-output" sequence kit. Consensus sequences from the sample were generated by de novo assembling using Genome Detective (https://www. genomedetective.com/) (5). Sequencing reads were mapped to NC_045512.2 (https://www.ncbi.nlm. nih.gov/nuccore/NC_045512.2) (Length: 29903bp) reference genome.
The new whole-genome sequences generated were assigned, according to the Pangolin (6) lineage classification, as the recently identified P.1 variant (B.1.1.28 lineage GR/501Y.V3_20J variant) (Supplementary data 1). In addition to the $\mathrm{E} 484 \mathrm{~K}$ mutation, it also has L18F (21614C>T), T20N (21621C>A), P26S (21638C >T), D138Y (21974G>T), R190S (22132G>T), K417T $(22812 A>C), \quad N 501 Y \quad(23063 A>T), \quad$ D614G (23403A>G), H655Y (23525C > T), T1027I (24642C > T) and V1176F $(25088 \mathrm{G}>\mathrm{T})$ in the spike region, characterizing the P.1 lineage 501Y.V3 variant associated with increased binding to the human ACE2 receptor: a protein on the cell surface functioning as an entrance into the cell for SARS-CoV-2. The all genomic changing properties are C241T, T733C, C2749T, C3037T, C3828T, C5147T, A5648C, A6319G, A6613G, C12778T, C13860T, C14408T, C14925T, G17259T, C18647A, C21614T, C21621A, C21638T, G21974T, G22132T, A22812C, G23012A, A23063T, A23403G, C23525T, C24642T, G25088T, T26149C, G28167A, C28512G, A28877T, G28878C, G28881A, G28882A and G28883C substitutions, 11288 and 11297 deletions, 28269:AAAC insertion (Supplementary data 2).

\section{DISCUSSION}

This Gamma variant has its origins in the B.1.1.28 clade and was first noticed in Japan among people coming from Brazil and first detected in sequences from patients in Rio de Janeiro state, collected in October 2020. However, based on phylogenetic analysis, the variant likely originated in July 2020 (7). Despite very high infection rates in the Amazon region, the second wave of infection hit Manaus, the largest urban metropolis in the Amazon, where high rates of population immunity had been observed between December 2020 and January 2021. Genomic sequencing of clinical samples from Manaus found that this second wave was associated with the emergence and rapid spread of a new VOC, the P.1 lineage. This variant likely arose from the Amazonas (AM) region of Brazil. Hence, Naveca et al. (8) designated this variant as 28-AM-II. In addition, another variant which shares the K417T, E484K, N501Y mutations also arose independently from this B.1.1.28 lineage from Amazonas, which is designated as 28-AM-I.8 Both these variants have also been assigned a designation of P.1 variant as 
part of the B.1.1.28 nomenclature. This lineage has been identified in over 20 countries worldwide and continues to spread, including; England, Singapore, the USA, Norway, Argentina, Denmark, Ireland and Canada. The E484K mutation, in particular, is of interest due to evidence that it may allow immune escape $(9,10)$. Further study is needed to demonstrate whether these mutations will impact immune, or indeed vaccine, response. Differences in clinical severity of COVID-19 with these variants has not been clarified so far. However, findings point to a risk of reinfection and enhanced transmissibility similar to the South African variant as they share a similar pattern of mutations (N501Y, E484K, K417N/T) (11).

\section{CONCLUSION}

The Turkish government's response on detection of these variants was to continue to advise their citizens of the need for maintaining social distance, adherence to hygiene rules, mask use and avoiding non-essential trips and social activities (12). Global collaborative efforts on rapid virus genome sequencing allow us to identify SARS-CoV-2 lineages of concerns in near real-time. Nevertheless, the uncertainty in the way SARS-CoV-2 changes, early detection of variants and the sustainability of vaccine efficacy require much more sequencing and analysis of virus genomes globally.

\section{Informed Consent: N/A}

Peer-review: Externally peer-reviewed

Author Contributions: Concept - K.M., M.A.K., Y.T.T., S.Ş.Y.; Design - K.M., Y.T.T., M.A.K.; Supervision - K.M., M.A.K., S.Ş.Y., F.C.; Funding - K.M., M.A.K., F.C.; Materials -Y.T.T., M.A.K., E.Y., O.K.N., Z.Z.; Data Collection and/or Processing - .S..Y., Z.A., Y.T.T., K.M., E.Y.; Analysis and/or Interpretation - O.K.N., Y.T.T., S.Ş.Y., H.E., K.M., M.A.K.;
Literature Review - Y.T.T., S.S..Y., H.E., K.M., Z.A., E.Y.; Writer - Y.T.T., M.A.K., K.M., H.E., O.K.N.; Critical Reviews - S.Ş.Y., H.E., K.M., F.C.

Conflict of Interest: The authors have no conflict of interest to declare.

Financial Disclosure: The authors declared that this study has received no financial support.

\section{REFERENCES}

1 Risk Assessment: Risk related to spread of new SARS-CoV-2 variants of concern in the EU/EEA [Internet]. European Centre for Disease Prevention and Control. (December 29, 2020; cited May 3, 2021). Available from: https://www.ecdc.europa.eu/en/publications-data/covid-19-risk-assessment-spread-new-sars-cov-2variants-eueea\#no-link

2 Scheuber A, L Van Elsland S. More transmissible and evasive SARS-CoV-2 variant growing rapidly in Brazil [Internet]. Imperial College London News. (March 02, 2020; cited May 3, 2021) Available from: https://www.imperial.ac.uk/news/216053/moretransmissible-evasive-sars-cov-2-variant-growing/

3 GISAID [Internet]. (Dec 24, 2020; cited May 03, 2021). Available from: https://www.gisaid.org/

4 Korukluoglu G, Kolukirik M, Bayrakdar F, Girgin Ozgumus G, Altas AB, Cosgun Y, et al. 40 minutes RT-qPCR assay for screening spike N501Y and HV69-70del mutations. bioRxiv 2021.01.26.428302. [CrossRef]

5 Cleemput S, Dumon W, Fonseca V, Abdool Karim W, Giovanetti M, Alcantara LC, et al. Genome detective coronavirus typing tool for rapid identification and characterization of novel coronavirus genomes. Bioinformatics. June 1, 2020;36;3552-5. [CrossRef]

6 O'Toole Á, Scher E, Underwood A, Jackson B, Hill V, McCrone JT, et al. Assignment of Epidemiological Lineages in an Emerging Pandemic Using the Pangolin Tool, Virus Evolution 2021; veab064. [CrossRef]

7 Voloch CM, da Silva Francisco R Jr, de Almeida LGP, Cardoso CC, Brustolini OJ, Gerber AL, et al. Genomic characterization of a nov- el SARS-CoV-2 lineage from Rio de Janeiro, Brazil. J Virol. Mar 1, 2021;95(10):e00119-21. [Epub ahead of print] [CrossRef]

8 Naveca F, Nascimentio V, Souza V, Corado A, Nascimento, Sila G, et al. Phylogenetic relationship of SARSCoV-2 sequences from Amazonas with emerging Brazilian variants harboring mutations E484K and N501Y in the Spike protein [Internet]. Virological. (January 11, 2021; cited May 03, 2021). Available from: https://virological.org/t/phylogenetic-relationship-of-sars-cov-2-sequences-from-amazonas-with-emerging-brazilian-variants-harboringmutations-e484k-and-n501y-in-the-spike-protein/585

9 Nonaka CKV, Franco MM, Gräf T, Mendes AV, de Aguiar SR, Giovanetti M, et al. Genomic evidence of a Sars-Cov-2 reinfection case with E484K spike mutation in Brazil. Preprints 2021, 2021010132. [CrossRef]

10 Resende PC, Bezerra JF, de Vasconcelos RHT, Arantes I, Appolinario L, Medonça A, et al. Spike E484K mutation in the first SARSCoV-2 reinfection case confirmed in Brazil. [Internet]. Virological. (January 10, 2021; cited May 03, 2021). Available from: https:// virological.org/t/spike-e484k-mutation-in-the-first-sars-cov-2reinfection-case-confirmed-in-brazil-2020/584

11 Tang JW, Toovey OTR, Harvey KN, Hui DDS. Introduction of the South African SARS-CoV-2 variant 501Y.V2 into the UK. J Infect. Jan 17, 2021. [Epub ahead of print]. [CrossRef]

12 COVID-19 Bilgilendirme Platformu [Internet]. T.C. Sağllk Bakanlığı. (September 03, 2020; cited May 03, 2021). Turkish. Available from: https://covid19.saglik.gov.tr/TR-66301/ covid-19-rehberi.html 